\title{
Patients' awareness of the potential benefit of smoking cessation. A study evaluating self-reported and clinical data from patients referred to an oral medicine unit
}

\author{
Michael M. Bornstein • Marc Frei • Pedram Sendi • \\ Christoph A. Ramseier • Peter A. Reichart
}

Received: 26 April 2010 / Accepted: 15 November 2010/Published online: 1 December 2010

(C) Springer-Verlag 2010

\begin{abstract}
The present study analyzed history of smoking and willingness to quit smoking in patients referred for diagnosis and treatment of different oral mucosal lesions. Prior to the initial clinical examination, patients filled in a standardized questionnaire regarding their current and former smoking habits and willingness to quit. Definitive diagnoses were classified into three groups (benign/reactive lesions, premalignant lesions and conditions, and malignant diseases) and correlated with the self-reported data in the questionnaires. Of the 980 patients included, 514 (52\%) described themselves as never smokers, $202(21 \%)$ as former smokers, and $264(27 \%)$ as current smokers. In the group of current smokers, $23 \%$ thought their premalignant lesions/conditions were related to their smoking habit, but only $15 \%$ of the patients with malignant mucosal diseases saw that correlation. Only $14 \%$ of the smokers wanted to commence smoking cessation within the next 30 days. Patients with malignant diseases (31\%) showed greater willingness to quit than patients diagnosed with benign/ reactive lesions (11\%). Future clinical studies should attempt (1) to enhance patients' awareness of the negative
\end{abstract}

\footnotetext{
M. M. Bornstein $(\bowtie) \cdot$ M. Frei $\cdot$ P. A. Reichart

Department of Oral Surgery and Stomatology,

School of Dental Medicine, University of Bern,

Freiburgstrasse 7,

CH-3010, Bern, Switzerland

e-mail: michael.bornstein@zmk.unibe.ch

P. Sendi

Institute for Clinical Epidemiology and Biostatistics,

Basel University Hospital,

Basel, Switzerland

C. A. Ramseier

Department of Periodontology, School of Dental Medicine,

University of Bern,

Bern, Switzerland
}

impact of smoking on the oral mucosa and (2) to increase willingness to quit in smokers referred to a dental/oral medicine setting.

Keywords Smoking · Oral diseases - Willingness to quit . Smoking cessation

\section{Introduction}

Smoking harms nearly every organ of the body, leading to a range of morbidities and premature mortality. There are some 4,000 known chemicals in tobacco smoke; more than 50 of them are known to cause cancer in humans. The lung is the site considered at highest relative risk of cancer due to smoking [1]. Following lung cancer, the highest relative risks are observed for the larynx and oral cavity [2]. A recent meta-analysis reported 12 studies that estimated oral cancer risk in the USA, Uruguay, Italy, Sweden, India, China, Taiwan, and Korea [3]. The reported pooled cancer risk estimate was 3.43 times higher in smokers compared with nonsmokers. Besides oral cancer, other oral diseases that have been considered related to cigarette smoking include oral precancer, periodontal disease, caries and tooth loss, gingival recession, and other benign mucosal disorders such as smoker's melanosis and smoker's palate $[4,5]$.

Primary prevention focuses on eliminating risk factors in order to reduce the number of cases of certain diseases. Since the risk factors for oral cancer and precancer are well known (tobacco, heavy drinking, poor diet), the oral health team should act both on the community level as well as in its clinical environment [6]. In most countries, the simple scheme of the five As is applied in smoking cessation efforts: Ask patients about their tobacco habits, Advise them to quit smoking, Assess patient's willingness to quit, 
Assist them in achieving this, and Arrange follow-up [7]. The integration and success of tobacco cessation counseling in a dental practice setting involves changes in the knowledge, attitudes, and behavior of both dental team members and their patients. Johnson [8] has identified many possible barriers to the required changes including lack of time to spend counseling, lack of training and skills, legal limitations on prescribing nicotine replacement therapy (NRT), added costs of the counseling, and client/patient resistance to quitting smoking.

The aim of the present study was to analyze the willingness to quit smoking in patients referred to an oral medicine unit for diagnosis and treatment of different mucosal lesions. Primary outcome parameters evaluated were a potential relationship between the type of lesion (benign, premalignant, and malignant) and a subjective appraisal of patients' perception of the benefits following smoking cessation, obtained with a standardized questionnaire.

\section{Material and methods}

Study sample and clinical examination

The present study included all patients referred to the oral medicine unit at the Department of Oral Surgery and Stomatology, University of Bern, for diagnosis and treatment of oral mucosal lesions in the period from January 2007 to June 2009 . The study protocol was approved by the standing ethical committee for clinical studies of the Medical Faculty, University of Bern. All patients were examined following the same protocol by residents of the department, including thorough medical history, recent dental/stomatological history, extraoral and intraoral examination, and oral biopsy and radiographic imaging where necessary. Based on the findings of the clinical and eventual histopathological examinations, a definitive diagnosis was formulated and classified in one of three groups: benign/reactive lesions, premalignant lesions and conditions, or malignant diseases of the oral mucosa. All smokers underwent brief counseling for smoking cessation (behavioral intervention) including the prescription of NRT (pharmacological intervention) where indicated, as recommended in the consensus report of the First European Workshop on Tobacco Use Prevention and Cessation for Oral Health Professionals [9].

Assessment of smoking status and questionnaire data

- Before commencement of the initial examination at the department, all patients had to fill in a standardized questionnaire regarding their current and former smoking habits and their willingness to quit [10].
This questionnaire included the following parameters: History of smoking: All patients were asked whether they were never smokers, former smokers or current smokers. The current and former smokers had to indicate the number of cigarettes smoked per day (including the time period since they started smoking) to allow for calculation of a pack year value.

- Current smokers were asked if they thought that their mucosal problems were related to their smoking habit. The answers were classified according to the following index:

$0=$ No correlation between smoking and mucosal lesion

1 = Not clear/maybe some relationship between smoking and mucosal lesion

$2=$ Clear relationship between smoking and mucosal lesion

- Additionally, current smokers were asked whether they thought their oral lesions would benefit from smoking cessation. The answers were grouped according to the following index:

$0=$ No benefit from smoking cessation

$1=$ Not clear/maybe some benefit from smoking cessation

$2=$ Clear benefit from smoking cessation

- All smokers were asked if they were willing to quit smoking, and if so, when they would like to commence their cessation. The answers were classified according to the following index:

$0=$ Not interested in smoking cessation at all $1=$ Not interested in smoking cessation at the moment, maybe in half a year

$2=$ Interested in smoking cessation during the next 30 days

- Finally, a history of smoking cessation efforts was recorded for all smokers, including the use of NRT (yes/no answer). The following index was used:

$0=$ No previous smoking cessation effort

$1=$ One previous smoking cessation effort

$2=$ Two to four previous smoking cessation efforts

$3=$ More than four previous smoking cessation efforts

Statistical analysis

First, all data were analyzed using descriptive methods. To detect significant differences or potential influencing factors associated with a history of smoking as derived from the patient questionnaire, we complemented all relevant point estimates with $95 \%$ confidence intervals. Among smokers, 
we estimated the odds ratios for (i) the patient's willingness to quit, (ii) the patient's perception of the benefits of smoking cessation, and (iii) the patient's view about any association between smoking and oral lesions for the three different types of lesions. In addition, we estimated the $95 \%$ confidence interval of the respective odds ratios. All statistical analyses were performed using S-Plus Professional (Insightful Corp., Seattle, WA, USA).

\section{Results}

\section{Study population}

During the study period from January 2007 to June 2009, 1,044 patients were referred to the oral medicine unit at the Department of Oral Surgery and Stomatology. A number of 39 patients had to be excluded from further analysis due to missing data in the smoking status evaluation section of the questionnaire. Additionally, 25 patients were not included due to an unclear final diagnosis. Therefore, a total of 980 patients were included in the present study. This group comprised 453 male and 527 female participants with a mean age of 55.5 years (minimum 10 years, maximum 96 years).

The definitive diagnoses of the 980 patients included 741 benign/reactive mucosal lesions, 202 premalignant lesions and conditions, and 37 malignant soft tissue pathologies. In the group of benign/reactive mucosal lesions, fibrous hyperplasias were the most frequent finding $(n=138)$. Also, quite frequent findings were anatomic variations, with a total of 61 lesions (e.g., geographic tongue, Fordyce's spots, etc.). Diagnoses that were encountered fewer than ten times during the study period included lesions such as peripheral giant cell granulomas $(n=8)$, benign mucosal pemphigoid $(n=6)$, and pseudomembranous oral candidosis $(n=4)$. Only five diagnosed malignant tumors were not squamous cell carcinomas: a distant metastasis of colon carcinoma and adenocarcinoma of the lung, a Ewing's sarcoma, an atypical Burkitt lymphoma, and an adenoid cystic carcinoma.

\section{Questionnaire analysis}

The study population comprised a total of 466 current or former smokers ( $48 \%$ of 980 patients included). The percentage of current smokers for the different diagnoses varied between $0 \%$ and $96 \%$ of the patients (Table 1 ). Regarding the three disease groups (benign/reactive lesions, premalignant lesions and conditions, and malignant diseases of the oral mucosa), $55 \%$ of never smokers had benign lesions, whereas only $30 \%$ had malignant diseases including oral squamous cell carcinoma (Table 2). The mean pack year values were 22 for the benign/reactive lesions group, 30 for premalignant lesions, and 56 for malignant diseases. The $95 \%$ confidence intervals of the mean indicate that there is a statistically significant increase in pack years among patients with a malignant lesion.

Current smokers $(33 \%)$ indicated that they thought their premalignant lesions/conditions were related to their smoking habit, yielding an odds ratio of 2.43 (95\% CI $1.12-5.27 ; p<0.01)$ compared to smokers with a benign lesion. Only $15 \%$ of current smokers with malignant diseases acknowledged a correlation (Table 3); the odds ratio as compared to current smokers with benign lesions was 1.45 (95\% CI $0.29-7.09)$. Asked whether they thought their oral lesions would benefit from smoking cessation, $75 \%$ of current smokers in the group with benign/reactive lesions said yes, compared to $57 \%$ of current smokers in the malignant disease group (Table 4). The odds ratio for patients with malignant versus benign lesions was therefore 0.45 (95\% CI $0.14-1.39)$. For patients with a premalignant versus a malignant lesion, the odds ratio was 1.51 (95\% CI $0.71-3.21)$.

About half of the current smokers (49\%) did not want to quit smoking within the next 6 months. Overall, only 14\% of the smokers wanted to commence smoking cessation within the next 30 days. There was greater willingness to quit among smokers with malignant diseases $(11 \%$ for benign/reactive versus $31 \%$ for malignant lesions; Table 5), yielding an odds ratio of 3.76 (95\% CI 1.03-13.72; $p<0.01$ ). For smokers with a premalignant versus a benign lesion, the corresponding odds ratio for willingness to quit was 1.94 (95\% CI $0.83-4.52$ ). Accordingly, $38 \%$ of the smokers with malignant mucosal diseases indicated no interest in quitting smoking, whereas $53 \%$ of the smokers with benign/reactive lesions were not interested.

Regarding history of smoking cessation efforts, $32.5 \%$ of the current smokers reported no previous attempts to stop smoking. The percentage of smokers who had never before tried to quit ranged from $25 \%$ of current smokers with premalignant lesions and conditions to $33 \%$ of smokers with benign/reactive lesions to $58 \%$ of smokers with malignant oral lesions (Table 6). Most of the current smokers that had tried smoking cessation before reported more than one effort. Out of the 264 registered current smokers in the study, only 64 had tried NRT for a former smoking cessation effort.

\section{Discussion}

On a global scale, the use of tobacco products is increasing, although there is a clear trend toward a decrease in highincome countries. Overall in Europe, the prevalence of cigarette smoking has stabilized at around $28.6 \%$ in the 
Table 1 Distribution of never, former, and current smokers according to the different mucosal findings $(n>10$; percentages given, if group total $\geq$ 100)

\begin{tabular}{|c|c|c|c|c|}
\hline Diagnosis & Total & Never smoker $(\%)$ & Former smoker $(\%)$ & Current smoker (\%) \\
\hline Fibrous hyperplasia & 138 & $79(57 \%)$ & $27(20 \%)$ & $32(23 \%)$ \\
\hline Oral lichenoid lesions & 112 & $60(54 \%)$ & $38(34 \%)$ & $14(12 \%)$ \\
\hline Oral leukoplakia & 100 & $29(29 \%)$ & $14(14 \%)$ & $57(57 \%)$ \\
\hline Oral lichen planus & 100 & $61(61 \%)$ & $24(24 \%)$ & $15(15 \%)$ \\
\hline Anatomic variations & 61 & 35 & 10 & 16 \\
\hline Frictional hyperkaratosis & 53 & 26 & 7 & 20 \\
\hline Oral squamous cell carcinoma & 32 & 9 & 8 & 15 \\
\hline Mucocele & 31 & 21 & 4 & 6 \\
\hline Papilloma & 31 & 11 & 6 & 14 \\
\hline Tobacco-related lesions $^{\mathrm{a}}$ & 27 & - & 1 & 26 \\
\hline Vascular malformation (e.g., hemangioma) & 22 & 8 & 11 & 3 \\
\hline Recurrent aphthous stomatitis & 19 & 11 & 6 & 2 \\
\hline Tongue-tie/frenulum & 19 & 19 & - & - \\
\hline Sialadenitis/sialolithiasis & 18 & 13 & 2 & 3 \\
\hline Burning mouth syndrome (BMS) & 18 & 12 & 2 & 4 \\
\hline Pyogenic granuloma & 16 & 10 & 5 & 1 \\
\hline Bisphosphonate-related osteonecrosis of the jaws (BRONJ) & 15 & 10 & 3 & 2 \\
\hline Amalgam tattoo & 12 & 8 & 3 & 1 \\
\hline Lipoma & 10 & 3 & 3 & 4 \\
\hline Other lesions $(n<10)$ & 146 & $89(61 \%)$ & $28(19 \%)$ & $29(20 \%)$ \\
\hline Total & 980 & $514(52 \%)$ & $202(21 \%)$ & $264(27 \%)$ \\
\hline
\end{tabular}

${ }^{\text {a }}$ Smokers' melanosis and smokers' palate

adult population ( $40 \%$ males versus $18.2 \%$ females), and there is no visible decline for countries in southern and eastern Europe such as Greece, with a total of over $50 \%$ smokers (male 63.6\%, female 39.8\%; [11, 12]). In the present study, the patients analyzed were rather representative of an average European population, with $27 \%$ being smokers. Although the patients referred to an oral medicine unit represent a selective population, and a higher percentage of smokers could have been suspected initially, this was not substantiated by the present findings. Nevertheless, there was a pronounced difference of percentages of current smokers present in the three different groups of oral lesions, with $24 \%$ of current smokers having benign/reactive lesions and $43 \%$ of current smokers presenting with malignant mucosal diseases.

The most important etiological factors for the development of oral cancer are tobacco [5], excess consumption of alcohol [13], and betel quid usage in South and Southeast Asia $[14,15]$. These factors act separately or synergistically. Heavy drinkers and smokers have 38 times greater risk than abstainers from both products [16]. In a study from northern Italy, the single factor with the highest attributable risk for oral cancer development was smoking [17], and this risk was related to both intensity and duration of tobacco smoking [18]. The dose effect of tobacco was also demonstrated in the present study, where the mean pack

Table 2 Distribution of never, former and current smokers according to three different groups of mucosal findings

\begin{tabular}{|c|c|c|c|c|c|c|}
\hline Group & Total & $\begin{array}{l}\text { Never smoker } \\
(\%)\end{array}$ & $\begin{array}{l}\text { Former } \\
\text { smoker }(\%)\end{array}$ & $\begin{array}{l}\text { Current } \\
\text { smoker (\%) }\end{array}$ & $\begin{array}{l}\text { Current smokers } \\
\text { male }(\%)\end{array}$ & $\begin{array}{l}\text { Current smokers mean py } \\
(95 \% \mathrm{CI})\end{array}$ \\
\hline Benign/reactive lesion & 741 & $411(55 \%)$ & $154(24 \%)$ & $176(24 \%)$ & $99(56 \%)$ & $22(19-25)$ \\
\hline $\begin{array}{l}\text { Premalignant lesions and } \\
\text { conditions }\end{array}$ & 202 & $92(45.5 \%)$ & $38(19 \%)$ & $72(35.5 \%)$ & $43(60 \%)$ & $30(25-35)$ \\
\hline Malignant diseases & 37 & $11(30 \%)$ & $10(27 \%)$ & $16(43 \%)$ & $11(69 \%)$ & $56(36-76)$ \\
\hline Total & 980 & $514(52 \%)$ & $202(21 \%)$ & $264(27 \%)$ & $153(58 \%)$ & - \\
\hline
\end{tabular}

py Cumulative pack years, defined as 20 manufactured cigarettes/one pack smoked per day for 1 year, $C I$ confidence interval 
Table 3 Correlation between the smoking habit and the mucosal findings as assessed by the current smokers in the three groups of diseases analyzed

\begin{tabular}{|c|c|c|c|c|}
\hline \multirow[b]{2}{*}{ Group } & \multicolumn{4}{|c|}{ Correlation smoking and mucosal lesion } \\
\hline & $0(\%$ and $95 \% \mathrm{CI})$ & $1(\%$ and $95 \% \mathrm{CI})$ & $2(\%$ and $95 \% \mathrm{CI})$ & Row total \\
\hline Benign/reactive lesion & $108(67 \%$ and $\pm 7.2 \%)$ & $36(22 \%$ and $\pm 6.4 \%)$ & $18(11 \%$ and $\pm 4.8 \%)$ & $162^{\mathrm{b}}$ \\
\hline Premalignant lesions and conditions & $24(40 \%$ and $\pm 12.4 \%)$ & $22(37 \%$ and $\pm 12.9 \%)$ & $14(23 \%$ and $\pm 10.7 \%)$ & $60^{\mathrm{c}}$ \\
\hline Malignant diseases ${ }^{\mathrm{a}}$ & $8(62 \%$ and $\pm 26.4 \%)$ & $3(23 \%$ and $\pm 22.9 \%)$ & $2(15 \%$ and $\pm 19.6 \%)$ & $13^{\mathrm{d}}$ \\
\hline Column total & $140(60 \%)$ & $61(26 \%)$ & $34(14 \%)$ & 235 \\
\hline
\end{tabular}

0 No correlation between smoking and mucosal lesion, 1 not clear/maybe some relationship between smoking and mucosal lesion, 2 clear relationship between smoking and mucosal lesion, $95 \%$ CI $95 \%$ confidence interval

${ }^{\text {a }}$ Group comprises 12 squamous cell carcinomas and one distant metastasis of an adenocarcinoma of the lung

${ }^{\mathrm{b}}$ Answers missing: 14

${ }^{\mathrm{c}}$ Answers missing: 12

${ }^{\mathrm{d}}$ Answers missing: 3

year value for current smokers with malignant mucosal diseases was 56 , and the $95 \%$ confidence intervals of the mean indicate that there is a statistically significant increase in pack years over the three groups of diseases.

Although some studies suggest that smokers know the potentially harmful effects of smoking such as lung cancer $[19,20])$, there is also literature demonstrating that more education is needed to inform patients of the other, lesserknown health risks of cigarette smoking, such as reproduction-related problems and cancers other than lung cancer [21-23]. There are few studies assessing patient awareness of negative effects of cigarette smoking on oral health. A questionnaire study from 12 dental centers in Kuwait [24] reported that a majority of included patients were aware of smoking effects on tooth staining (89.5\% of all subjects). Awareness levels decreased with variables such as periodontal health $(76.2 \%)$, oral cancer $(62.2 \%)$, and wound healing $(27.7 \%)$. Fewer smokers than nonsmokers thought that oral health and smoking are related $(92.2 \%$ vs.
95.8\%) and that smoking affected oral cancer $(52.4 \%$ vs. $66.8 \%$ ). Logistic regression analysis showed smokers to be significantly less aware of the oral health effects of smoking than nonsmoking patients. Similar results were reported for a study from the UK questioning 1,000 subjects [25]. In that survey, $78 \%$ of the patients were aware that smoking had a negative impact on health. However, $52 \%$ of patients who were aware of the negative impact could not state what the negative effects were on oral health. Similar findings were also reported for another study asking 152 patients after treatment for oral cancer about their smoking habits, alcohol consumption, and their understanding of the part these factors play in the development of malignancy [26]. At least 6 months after the diagnosis of their malignancy, 72 (47\%) still smoked and 55 (36\%) drank alcohol to excess. Only one third were aware that their addiction had an impact on the development of oral cancer.

In the present study, only $14 \%$ of the smokers questioned indicated that they thought there was a clear relationship

Table 4 Potential benefit of smoking cessation as estimated by the current smokers in the three groups of diseases analyzed

\begin{tabular}{|c|c|c|c|c|}
\hline \multirow[b]{2}{*}{ Group } & \multicolumn{4}{|c|}{ Benefit of smoking cessation on mucosal lesion } \\
\hline & $0(\%$ and $95 \% \mathrm{CI})$ & $1(\%$ and $95 \% \mathrm{CI})$ & $2(\%$ and $95 \% \mathrm{CI})$ & Row total \\
\hline Benign/reactive lesion & $18(12 \%$ and $\pm 5.3 \%)$ & $19(13 \%$ and $\pm 5.5 \%)$ & $109(75 \%$ and $\pm 7.6 \%$ & $146^{\mathrm{b}}$ \\
\hline Premalignant lesions and conditions & $8(13 \%$ and $\pm 8.6 \%)$ & $3(5 \%$ and $\pm 5.5 \%)$ & $49(82 \%$ and $\pm 9.8 \%)$ & $60^{\mathrm{c}}$ \\
\hline Malignant diseases ${ }^{\mathrm{a}}$ & $1(7 \%$ and $\pm 13.5 \%)$ & $5(36 \%$ and $\pm 25.1 \%)$ & $8(57 \%$ and $\pm 25.9 \%)$ & $14^{\mathrm{d}}$ \\
\hline Column total & $27(12 \%)$ & $27(12 \%)$ & $166(76 \%)$ & 220 \\
\hline
\end{tabular}

0 No benefit from smoking cessation, 1 not clear/maybe some benefit from smoking cessation, 2 clear benefit from smoking cessation, $95 \%$ CI $95 \%$ confidence interval

${ }^{\text {a }}$ Group comprises 13 squamous cell carcinomas and one distant metastasis of an adenocarcinoma of the lung

${ }^{\mathrm{b}}$ Answers missing: 30

${ }^{\mathrm{c}}$ Answers missing: 12

${ }^{\mathrm{d}}$ Answers missing: 2 
Table 5 Willingness to quit smoking reported by the current smokers in the three groups of mucosal lesions analyzed

\begin{tabular}{|c|c|c|c|c|}
\hline \multirow[b]{2}{*}{ Group } & \multicolumn{4}{|c|}{ Willingness to quit smoking } \\
\hline & $0(\%$ and $95 \% \mathrm{CI})$ & $1(\%$ and $95 \% \mathrm{CI})$ & $2(\%$ and $95 \% \mathrm{CI})$ & Row total \\
\hline Benign/reactive lesion & $75(53$ and $\pm 8.2 \%)$ & $52(36.5$ and $\pm 7.9 \%)$ & $15(10.5$ and $\pm 5.0 \%)$ & $142^{\mathrm{b}}$ \\
\hline Premalignant lesions and conditions & $24(40.5$ and $\pm 12.5 \%)$ & $24(40.5$ and $\pm 12.5 \%)$ & $11(19$ and $\pm 9.9 \%)$ & $59^{\mathrm{c}}$ \\
\hline Malignant diseases ${ }^{\mathrm{a}}$ & $5(38$ and $\pm 26.4 \%)$ & $4(31$ and $\pm 25.1 \%)$ & $4(31$ and $\pm 25.1 \%)$ & $13^{\mathrm{d}}$ \\
\hline Column total & $104(49 \%)$ & $80(37 \%)$ & $30(14 \%)$ & 214 \\
\hline
\end{tabular}

0 Not interested in smoking cessation at all, 1 not interested in smoking cessation at the moment, maybe in half a year, 2 interested in smoking cessation during the next 30 days, $95 \%$ CI 95\% confidence interval

${ }^{\text {a }}$ Group comprises 12 squamous cell carcinomas and one distant metastasis of an adenocarcinoma of the lung

${ }^{\mathrm{b}}$ Answers missing: 34

${ }^{\mathrm{c}}$ Answers missing: 13

${ }^{\mathrm{d}}$ Answers missing: 3

between smoking and their mucosal lesion. But in contrast to the studies mentioned above, the patients were not knowledgeable about the definite diagnosis when answering the questionnaire before the initial clinical examination. All they knew about their respective mucosal findings was what the referring dentist had told them. Interestingly, patients with premalignant conditions/lesions were more aware of a correlation between smoking and their mucosal lesion, exhibiting a statistically significant odds ratio of $2.43(95 \%$ CI $1.12-5.27, p<0.01)$ as compared to patients with a benign lesion.

The significance of dentists' role in supporting their patients' attempts to discontinue tobacco use was first mentioned by Christen [27]. Since this initial report, tobacco use interventions in the dental setting have consistently shown to increase the odds of quitting [7, 28, 29]. Additionally, although patients expect their oral health care providers to ask about their tobacco use history [3032], many dental professionals express discomfort about implementing tobacco use prevention and cessation
(TUPAC) strategies in their routine care. These barriers include the possibility of dental patients being offended by discussions of smoking cessation and therefore account for the reason that only $33-50 \%$ of dentists routinely ask their patients about their tobacco dependence [7]. Other barriers to the implementation of TUPAC have been identified such as (i) lack of financial incentives or resources, (ii) assumptions that patients will not cooperate, (iii) tobacco use by oral health professionals, (iv) frustration over low success rates, (v) lack of visible effects of tobacco use in the oral cavity, (vi) low cost-benefit ratio, and (vii) discomfort in discussing tobacco use cessation $[7,8]$.

In order to potentially reduce these barriers and to facilitate the adoption of TUPAC strategies by dental practitioners, a level of care model involving a step-bystep strategy was recently proposed in the consensus report of the 2nd European Workshop on Tobacco Use Prevention and Cessation for Oral Health Professionals, to give dental clinicians the freedom to offer a varied approach, according to their patients' needs $[33,34]$. Following this approach, in

Table 6 Previous smoking cessation efforts of the current smokers in the population evaluated

\begin{tabular}{|c|c|c|c|c|c|}
\hline \multirow[b]{2}{*}{ Group } & \multicolumn{5}{|c|}{ Smoking cessation efforts } \\
\hline & 0 & 1 & 2 & 3 & Row total \\
\hline Benign/reactive lesion & $50(33 \%)$ & $38(25 \%)$ & $49(32 \%)$ & $14(10 \%)$ & $151^{\mathrm{b}}$ \\
\hline Premalignant lesions and conditions & $15(25 \%)$ & $14(24 \%)$ & $24(41 \%)$ & $6(10 \%)$ & $59^{\mathrm{c}}$ \\
\hline Malignant diseases $^{\mathrm{a}}$ & $7(58 \%)$ & $2(17 \%)$ & $2(17 \%)$ & $1(8 \%)$ & $12^{\mathrm{d}}$ \\
\hline Column total & $72(32.5 \%)$ & $54(24.5 \%)$ & $75(33.5 \%)$ & $21(9.5 \%)$ & 222 \\
\hline
\end{tabular}

0 No previous smoking cessation effort, 1 one previous smoking cessation effort, 2 two to four previous smoking cessation efforts, 3 more than four previous smoking cessation efforts

${ }^{\text {a }}$ Group comprises 11 squamous cell carcinomas and one distant metastasis of an adenocarcinoma of the lung

b Answers missing: 25

${ }^{\mathrm{c}}$ Answers missing: 13

${ }^{\mathrm{d}}$ Answers missing: 4 
the oral medicine unit at the School of Dental Medicine, University of Bern, every patient is offered basic TUPAC care consisting of brief interventions to identify tobacco users, assess readiness to quit, request permission to readdress at a subsequent visit, and if preferred, refer for further TUPAC counseling.

In the present study population, there was greater willingness to quit smoking in patients with malignant diseases ( $11 \%$ for benign/reactive versus $31 \%$ for malignant lesions), yielding a statistically significant odds ratio of 3.76 (95\% CI 1.03-13.72, $p<0.01)$. An inverse trend can be seen regarding the history of previous smoking cessation efforts, where the percentage of smokers who had never tried to stop smoking ranged from $25 \%$ of the current smokers with premalignant lesions and conditions to $33 \%$ of the smokers with benign/reactive lesions to $58 \%$ of the questioned smokers with malignant oral lesions.

To the best of our knowledge, the present study represents the first approach in the literature to assess patients' awareness of a possible relationship between their smoking habit and the mucosal disorders present, and their willingness to quit smoking. Nevertheless, the data presented has to be interpreted with some caution, as patients may have been already informed about the nature of their mucosal lesion (benign/reactive, premalignant, malignant), and its possible correlation with the harmful effects of smoking by their referring dentist. Furthermore, the study did not include smokeless tobacco in the questionnaire, thus, potentially underestimating the actual use of tobacco products by the patients evaluated. Future studies should take these possible confounders into account and should also try to validate subjective questionnaire data concerning tobacco use with objective methods, e.g., carbon monoxide or cotinine blood level testing. Whether current results for TUPAC [35-37] can be improved through more targeted identification of patients ready to quit smoking and the provision of alternate cessation strategies - including pharmacotherapy such as bupropion or varenicline - remains to be demonstrated in prospective clinical studies.

\section{Conclusions}

The present study demonstrates that patients referred to an oral medicine unit for treatment of a variety of oral mucosal diseases represent a percentage of current smokers (27\%) similar to that of the general Swiss population. Only a minority of the smokers questioned (14\%) saw a clear relationship between their smoking habit and the mucosal lesion present, whereas a majority $(76 \%)$ indicated that there could be a benefit from smoking cessation on the oral mucosa. Only $14 \%$ of the smokers were interested in undertaking a smoking cessation effort during the next
30 days, but there was significantly greater willingness to quit among patients with malignant diseases (odds ratio of 3.76) in comparison to patients with benign/reactive lesions. Future clinical studies should attempt (1) to enhance patients' awareness of the negative impact of smoking on the oral mucosa and (2) to increase willingness to quit in smokers referred to a dental/oral medicine setting.

Acknowledgments The study was supported by University of Bern departmental funds.

\section{Conflicts of interest None}

\section{References}

1. Patel RR, Ryu JH, Vassallo R (2008) Cigarette smoking and diffuse lung disease. Drugs 68:1511-1527

2. Gupta PC, Murti PR, Bhonsle RB (1996) Epidemiology of cancer by tobacco products and the significance of TSNA. Crit Rev Toxicol 26:183-198

3. Gandini S, Botteri E, Iodice S, Boniol M, Lowenfels $\mathrm{AB}$, Maisonneuve P, Boyle P (2008) Tobacco smoking and cancer: a meta-analysis. Int J Cancer 122:155-164

4. Johnson NW, Bain CA (2000) Tobacco and oral disease. EUWorking Group on Tobacco and Oral Health. Br Dent J 189:200 206

5. Warnakulasuriya S, Dietrich $\mathrm{T}$, Bornstein MM, Peidró EC, Preshaw PM, Walter C, Wennström JL, Bergström J (2010) Oral health risks of tobacco use and effects of cessation. Int Dent J 60:7-30

6. Reichart PA (2001) Identification of risk groups for oral precancer and cancer and preventive measures. Clin Oral Invest 5:307-213

7. Needleman I, Warnakulasuriya S, Sutherland G, Bornstein MM, Casals E, Dietrich T, Suvan J (2006) Evaluation of tobacco use cessation (TUC) counselling in the dental office. Oral Health Prev Dent 4:27-47

8. Johnson NW (2004) The role of the dental team in tobacco cessation. Eur J Dent Educ 8(suppl 4):18-24

9. Ramseier CA, Mattheos N, Needleman I, Watt R, Wickholm S (2006) Consensus report: first European workshop on tobacco use prevention and cessation for oral health professionals. Oral Health Prev Dent 4:7-18

10. Ramseier CA, Bornstein MM, Saxer UP, Klingler K, Walter C (2007) Tobacco use prevention and cessation in the dental practice. Schweiz Monatsschr Zahnmed 117:253-278 (in German)

11. Watt RG, Benzian H, Binnie V, Gafner C, Hovius M, Newton TJ, Mecklenburg RE (2006) Public health aspects of tobacco control: setting the agenda for action by oral health profession across Europe. Oral Health Prev Dent 4:19-26

12. Gallagher JE, Alajbeg I, Büchler S, Carrassi A, Hovius M, Jacobs A, Jenner M, Kinnunen T, Ulbricht S, Zoitopoulos L (2010) Public health aspects of Tobacco control revisited. Int Dent J 60:31-49

13. La Vecchia C, Tavani A, Franceschi S, Levi F, Corrao G, Negri E (1997) Epidemiology and prevention of oral cancer. Oral Oncol 33:302-312

14. Reichart PA, Way TH (2006) Oral cancer and pre-cancer in Myanmar: a short review. J Oral Pathol Med 35:193-196

15. Zhang X, Reichart PA (2007) A review of betel quid chewing, oral cancer and precancer in mainland China. Oral Oncol 43:424430

16. Blot WJ, McLaughlin JK, Winn DM, Austin DF, Greenberg RS, Preston-Martin S, Bernstein L, Schoenberg JB, Stemhagen A, 
Fraumeni JF Jr (1988) Smoking and drinking in relation to oral and pharyngeal cancer. Cancer Res 48:3282-3287

17. Negri E, La Vecchia C, Franceschi S, Tavani A (1993) Attributable risk for oral cancer in northern Italy. Cancer Epidemiol Biomarkers Prev 2:189-193

18. Gillison ML (2007) Current topics in the epidemiology of oral cavity and oropharyngeal cancers. Head Neck 29:779-792

19. Klesges RC, Somes G, Pascale RW, Klesges LM, Murphy M, Brown K, Williams E (1988) Knowledge and beliefs regarding the consequences of cigarette smoking and their relationships to smoking status in a biracial sample. Health Psychol 7:387-401

20. Strecher VJ, Kreuter MW, Kobrin SC (1995) Do cigarette smokers have unrealistic perceptions of their heart attack, cancer, and stroke risks? J Behav Med 18:45-54

21. Brownson RC, Jackson-Thompson J, Wilkerson JC, Davis JR, Owens NW, Fisher EB Jr (1992) Demographic and socioeconomic differences in beliefs about the health effects of smoking. Am J Public Health 82:99-103

22. Demierre MF, Brooks D, Koh HK, Geller AC (1999) Public knowledge, awareness, and perceptions of the association between skin aging and smoking. J Am Acad Dermatol 41:27-30

23. Oncken C, McKee S, Krishnan-Sarin S, O’Malley S, Mazure CM (2005) Knowledge and perceived risk of smoking-related conditions: a survey of cigarette smokers. Prev Med 40:779-784

24. Al-Shammari KF, Moussa MA, Al-Ansari JM, Al-Duwairy YS, Honkala EJ (2006) Dental patient awareness of smoking effects on oral health: comparison of smokers and non-smokers. J Dent 34:173-178

25. Lung ZH, Kelleher MG, Porter RW, Gonzalez J, Lung RF (2005) Poor patient awareness of the relationship between smoking and periodontal diseases. Br Dent J 199:731-737

26. Kerawala CJ (1999) Oral cancer, smoking and alcohol: the patients' perspective. Br J Oral Maxillofac Surg 37:374-376

27. Christen AG (1970) The dentist's role in helping patients to stop smoking. J Am Dent Assoc 81:1146-1152

28. Nohlert E, Tegelberg A, Tillgren P, Johansson P, Rosenblad A, Helgason AR (2009) Comparison of a high and a low intensity smoking cessation intervention in a dentistry setting in Sweden: a randomized trial. BMC Public Health 9:121
29. Needleman I, Binnie VI, Ainamo A, Carr AB, Fundak A, Koeber A, Öhrn K, Rosseel J (2010) Improving the effectiveness of tobacco use cessation (TUC). Int Dent J 60:50-59

30. Campbell HS, Sletten M, Petty T (1999) Patient perceptions of tobacco cessation services in dental offices. J Am Dent Assoc 130:219-226

31. Victoroff KZ, Lewis R, Ellis E, Ntragatakis M (2006) Patient receptivity to tobacco cessation counseling in an academic dental clinic: a patient survey. J Public Health Dent 66:209-211

32. Martinelli E, Palmer RM, Wilson RF, Newton JT (2008) Smoking behaviour and attitudes to periodontal health and quit smoking in patients with periodontal disease. J Clin Periodontol 35:944-954

33. Ramseier CA, Warnakulasuriya S, Needleman IG, Gallagher JE, Lahtinen A, Ainamo A, Alajbeg I, Albert D, Al-Hazmi N, Antohe E, Beck-Mannagetta J, Benzian H, Bergstrom J, Binnie V, Bornstein MM, Buchler S, Carr A, Carrassi A, Peidro EC, Compton S, Crail J, Crews K, Davis JM, Dietrich T, Enmark B, Fine J, Gallagher J, Jenner T, Forna D, Fundak A, Gyenes M, Hovius M, Jacobs A, Kinnunen T, Knevel R, Koerer A, Labella R, Lulic M, Mattheor N, McEwen A, Ohrn K, Polychronopoulou A, Preshaw P, Radley N, Rosseel J, Schoonheim-Klein M, Suvan J, Ulbricht S, Verstappen P, Walter C, Wennstrom J, Wickholm S, Zoitopoulos L (2010) Consensus report: 2nd European workshop on tobacco use prevention and cessation for oral health professionals. Int Dent J 60:3-6

34. Davies JM, Ramseier CA, Mattheos N, Schoonheim-Klein M, Compton S, Al-Hazmi N, Polychronopoulou A, Suvan J, Antohé ME, Forna D, Radley N (2010) Education of tobacco use prévention and cessation for dental professionals - a paradigm shift. Int Dent J 60:50-59

35. Severson HH, Andrews JA, Lichtenstein E, Gordon JS, Barckley MF (1998) Using the hygiene visit to deliver a tobacco cessation program: results of a randomized clinical trial. J Am Dent Assoc 129:993-999

36. Ebbert JO, Carr AB, Patten CA, Morris RA, Schroeder DR (2007) Tobacco use quitline enrollment through dental practices: a pilot study. J Am Dent Assoc 138:595-601

37. Binnie VI, McHugh S, Jenkins W, Borland W, Macpherson LM (2007) A randomised controlled trial of a smoking cessation intervention delivered by dental hygienists: a feasibility study. BMC Oral Health 7:5 